\title{
Preliminary report on effect of retinal panphotocoagulation on rubeosis iridis and neovascular glaucoma
}

\author{
LEILA LAATIKAINEN \\ From Moorfields Eye Hospital, City Road, London
}

SUMMARY Eight eyes with central retinal vein occlusion one eye with old central retinal artery occlusion complicated by rubeosis iridis or increased intraocular pressure, or both; and one eye with diabetic retinopathy and rubeosis iridis were treated by retinal panphotocoagulation. Vision did not improve but intraocular pressure was lower and iris neovascularisation regressed in most cases, supporting the hypothesis that retinal hypoxia is a cause of iris neovascularisation and suggesting that retinal panphotocoagulation has a potential prophylactic and therapeutic role in rubeosis iridis and early neovascular glaucoma.

Central retinal vein occlusion (CRVO) with capillary non-perfusion predisposes to retinal neovascularisation and rubeosis iridis (Laatikainen and Kohner, 1976). Studies on diabetic retinopathy suggest that destroying large areas of hypoxic retina or reducing its metabolic demands prevents neovascularisation and may cause retinal vessels to regress (Taylor, 1970). It was therefore decided to try this therapy in cases of retinal capillary non-perfusion and iris neovascularisation to see whether it would prevent neovascularisation or make it regress.

Rubeosis iridis may be associated with various eye diseases (Schulze, 1967), but the two most important causes of iris neovascularisation are diabetes and CRVO. In many cases rubeosis results in peripheral anterior synechiae and thrombotic or neovascular glaucoma. A follow-up study on CRVO showed that neovascular glaucoma appeared only in eyes with extensive retinal capillary non-perfusion, and in these eyes it was a common complication (Laatikainen and Kohner, 1976).

There is no known prophylactic treatment for rubeosis iridis, and neovascular glaucoma is often very resistant to any form of therapy. Obliteration of optic disc neovascularisation may occur after extensive photocoagulation of the hypoxic retina both in diabetes (Taylor, 1970) and after retinal branch vein occlusion (Kohner and Shilling, 1976). This paper is a preliminary report of the effect of

Address for reprints: Dr L. Laatikainen, University Eye Hospital, Haartmaninkatu 4 C, 00290 Helsinki 29, Finland retinal panphotocoagulation on rubeosis iridis and neovascular glaucoma.

\section{Material}

The material comprised 10 eyes. Eight of them had a recent CRVO. Of these eight, six had neovascular glaucoma, one had normal intraocular pressure in spite of rubeosis iridis, and one had raised intraocular pressure due to acute angle closure although there was no rubeosis. The ninth eye had neovascular glaucoma due to an old central retinal artery occlusion (CRAO) (or ischaemic type of CRVO) and the tenth eye had diabetic retinopathy and rubeosis iridis. Further clinical data on the 10 cases are summarised in the Table.

All eyes were treated by panretinal xenon arc photocoagulation avoiding the macular area. In most cases more than 400 burns of $4.5^{\circ}$ spot size were applied. All patients received a thorough ophthalmic examination, including fundus photography and fluorescein angiography as well as iris fluorescein angiography, both preoperatively and after treatment. A routine angiographic technique with either a fundus or slit-lamp camera and $5 \mathrm{ml}$ of 10 to $20 \%$ sodium fluorescein was used. The patients have been followed up for 6 to 19 months (mean 11 months) after photocoagulation.

\section{Results}

All eyes with CRVO had an ischaemic type of retinal response with extensive capillary closure 
Table Clinical data in 10 cases of neovascular glaucoma and/or rubeosis iridis before and after retinal panphotocoagulation

\begin{tabular}{|c|c|c|c|c|c|c|c|c|c|c|c|c|c|c|}
\hline \multirow[b]{2}{*}{$\begin{array}{l}\text { Case } \\
\text { No. }\end{array}$} & \multirow{2}{*}{$\begin{array}{l}\text { Preced- } \\
\text { ing eye } \\
\text { disease }\end{array}$} & \multicolumn{5}{|c|}{ Pretreatment } & \multirow{2}{*}{$\begin{array}{l}\text { Time of } \\
\text { treatment } \\
\text { after first } \\
\text { symptoms } \\
\text { (months) }\end{array}$} & \multirow{2}{*}{$\begin{array}{l}\text { Follow'-up } \\
\text { after } \\
\text { treatment } \\
\text { (months) }\end{array}$} & \multicolumn{6}{|c|}{ Posttreatment (latest) } \\
\hline & & $\begin{array}{l}\text { Visual } \\
\text { acuity }\end{array}$ & $\begin{array}{l}I O P \\
(\mathrm{mmHg})\end{array}$ & $\begin{array}{l}\text { Rubeo- } \\
\text { sis } \\
\text { iridis }\end{array}$ & $\begin{array}{l}\text { Cham- } \\
\text { ber } \\
\text { angle }\end{array}$ & $\begin{array}{l}\text { Pain } \\
\text { in eye }\end{array}$ & & & $\begin{array}{l}\text { Visual } \\
\text { acuity }\end{array}$ & $\begin{array}{l}I O P \\
(m m H g)\end{array}$ & $\begin{array}{l}\text { Rubeo- } \\
\text { sis } \\
\text { iridis }\end{array}$ & $\begin{array}{l}\text { Cham- } \\
\text { ber } \\
\text { angle }\end{array}$ & $\begin{array}{l}\text { Pain } \\
\text { in eye }\end{array}$ & $\begin{array}{l}\text { Other } \\
\text { treat- } \\
\text { ment }\end{array}$ \\
\hline 1 & CRVO & HM & 56 & ++ & $\begin{array}{l}\text { Open, } \\
\text { NV }\end{array}$ & No & 2 & 11 & HM & 25 & + & $\begin{array}{l}\frac{2}{3} \\
\text { closed }\end{array}$ & No & - \\
\hline 2 & CRVO & HM & 63 & ++ & Closed & Mild & 3 & 19 & NPL & 18 & + & $\begin{array}{l}\frac{1}{3} \\
\text { closed }\end{array}$ & No & - \\
\hline 3 & CRVO & HM & 35 & +1 & $\begin{array}{l}\frac{1}{2} \\
\text { closed }\end{array}$ & Mild & 8 & 13 & HM & 18 & + & $\begin{array}{l}\frac{1}{2} \\
\text { closed }\end{array}$ & No & $\begin{array}{l}\text { Pilo- } \\
\text { carpine }\end{array}$ \\
\hline 4 & CRVO & $\mathbf{H M}$ & 45 & ++ & $\begin{array}{l}\frac{3}{4} \\
\text { closed }\end{array}$ & Severe & 6 & 7 & NPL & 53 & + & Closed & No & - \\
\hline 5 & CRVO & CF & 47 & + & closed & No & 2 & 10 & HM & 32 & - & $\begin{array}{l}\frac{1}{4} \\
\text { closed }\end{array}$ & No & $\begin{array}{l}\text { Pilo- } \\
\text { carpine }\end{array}$ \\
\hline 6 & CRVO & $\mathrm{CF}$ & 60 & + & Closed & Severe & 0 & 6 & CF & 19 & - & $\begin{array}{l}\text { Open, } \\
\text { NV }\end{array}$ & No & - \\
\hline 7 & CRVO & CF & 38 & - & $\begin{array}{l}\frac{1}{2} \\
\text { closed }\end{array}$ & Mild & 1 & 14 & CF & 14 & - & Open & No & - \\
\hline 8 & CRVO & $\mathbf{H M}$ & 15 & ++ & $\begin{array}{l}\text { Open, } \\
\text { NV }\end{array}$ & No & 6 & 15 & NPL & 16 & - & $\begin{array}{l}\frac{1}{2} \\
\text { closed }\end{array}$ & No & - \\
\hline 9 & CRAO? & PL & 52 & ++ & $\begin{array}{l}\frac{1}{2} \\
\text { closed }\end{array}$ & Mild & 6 years & 8 & NPL & 30 & + & $\begin{array}{l}\frac{1}{2} \\
\text { closed }\end{array}$ & No & - \\
\hline 10 & $\begin{array}{l}\text { Diabetic } \\
\text { retino- } \\
\text { pathy }\end{array}$ & $6 / 12$ & 17 & ++ & $\begin{array}{l}\text { Open, } \\
\text { NV }\end{array}$ & No & 2 years & 8 & CF & 15 & - & Open & No & - \\
\hline
\end{tabular}

CRVO = central retinal vein occlusion, $\mathrm{CRAO}=$ central retinal artery occlusion, $\mathrm{IOP}=$ intraocular pressure, $\mathrm{CF}=$ counting fingers, HM = hand movements, PL = perception of light, NPL = no perception of light, $\mathrm{NV}=$ newly formed vessels.

(Fig. 1 A, B). Central visual acuity at the initial presentation, six weeks to eight months after the onset of symptoms, was poor in all cases (Table)namely, hand movements (HM) in five eyes and counting fingers $(C F)$ in three. At the latest examination the vision was unchanged in four eyes and had deteriorated in the others from CF to HM in one eye and from HM to no perception of light (NPL) in three.

Intraocular pressure (IOP) was raised in all but one eye with CRVO (case 8, Table) before photocoagulation, causing pain in five cases. Two eyes were painless in spite of raised IOP (56 and $47 \mathrm{mmHg}$ respectively). After photocoagulation IOP decreased considerably in all but two cases. In case 8 IOP was also normal before treatment and in case 4 it remained unchanged because of complete angle closure. In the latter eye the pressure varied from 39 to $53 \mathrm{mmHg}$ since treatment, but there was no discomfort in the eye and no other treatment was needed. In two cases pilocarpine drops were used after photocoagulation. The patient in one of these cases (case 5, Table) had chronic bilateral open-angle glaucoma. All eyes have been quiet and comfortable since photocoagulation.

Rubeosis iridis was present in all but one eye (case 7, Table), and in most cases neovascularisation was found both in the angle and around the pupil.
Iris fluorescein angiography showed leakage of the dye from the new vessels (Fig. 2 A) and in some cases also from the radial vessels (Fig. 3 B). After photocoagulation clinically visible rubeosis decreased in all cases and in four eyes no new vessels could be seen. Iris fluorescein angiography showed persistence of new vessels in some cases, but there was less leakage of dye from the neovascularisation (Fig. 2 A, B) and also less congestion and leakage of the radial iris vessels (Fig. 3 A-D).

Both the initial appearance and the posttreatment findings in the chamber angle varied. In two eyes the angle was initially open in spite of new vessel formation (cases 1 and 8, Table), but both eyes developed some peripheral synechiae after treatment. In two cases (cases 2 and 6, Table) the angle was completely closed at the time of the acute rise of pressure. After treatment no permanent peripheral synechiae were found in case 6 , and in case 2 synechiae closed less than half a circumference of the angle. In one eye with initially half-closed angle (case 7, Table) no rubeosis or synechiae were seen after photocoagulation, indicating the mechanism of acute angle closure attack in these cases. In two eyes (cases 3 and 5, Table) the amount of peripheral synechiae did not change after treatment, and in one eye (case 4, Table) the angle closed completely.

In case 9 (Table) rubeosis iridis and neovascular glaucoma had developed after presumptive central 

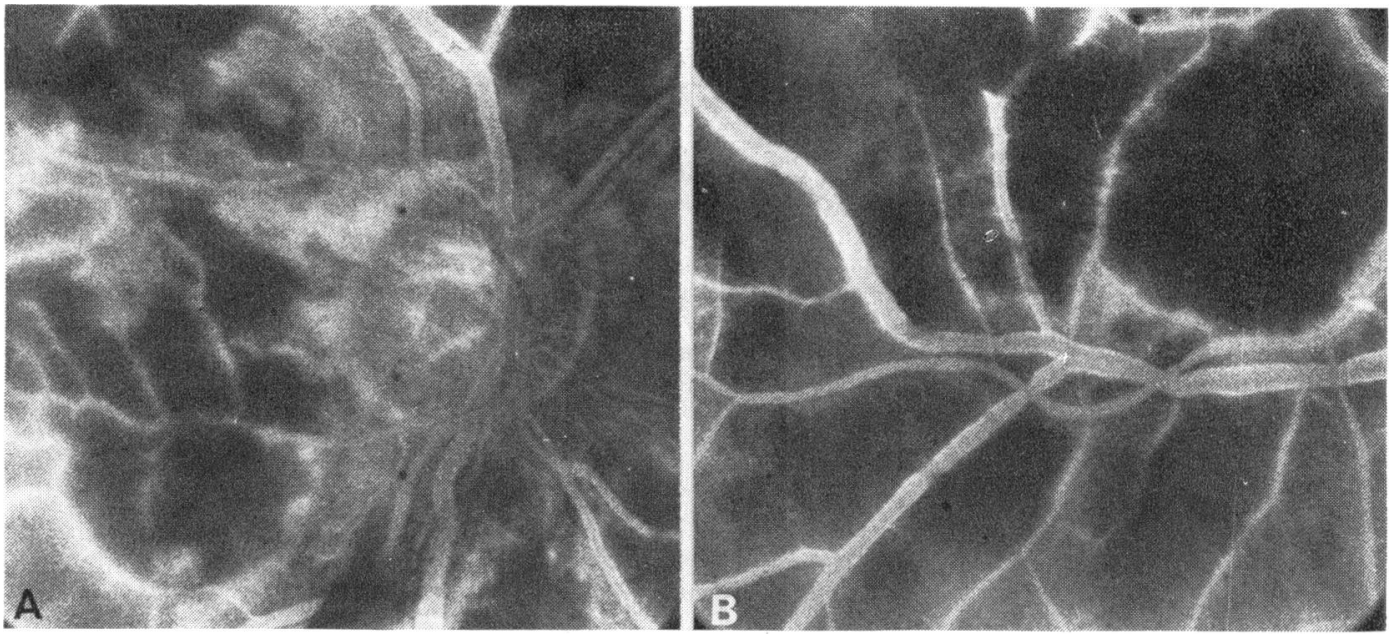

Fig. 1 Case 6. Fluorescein angiogram of optic disc (A) and lower temporal area (B) showing complete capillary closure and leakage of dye from remaining vessels
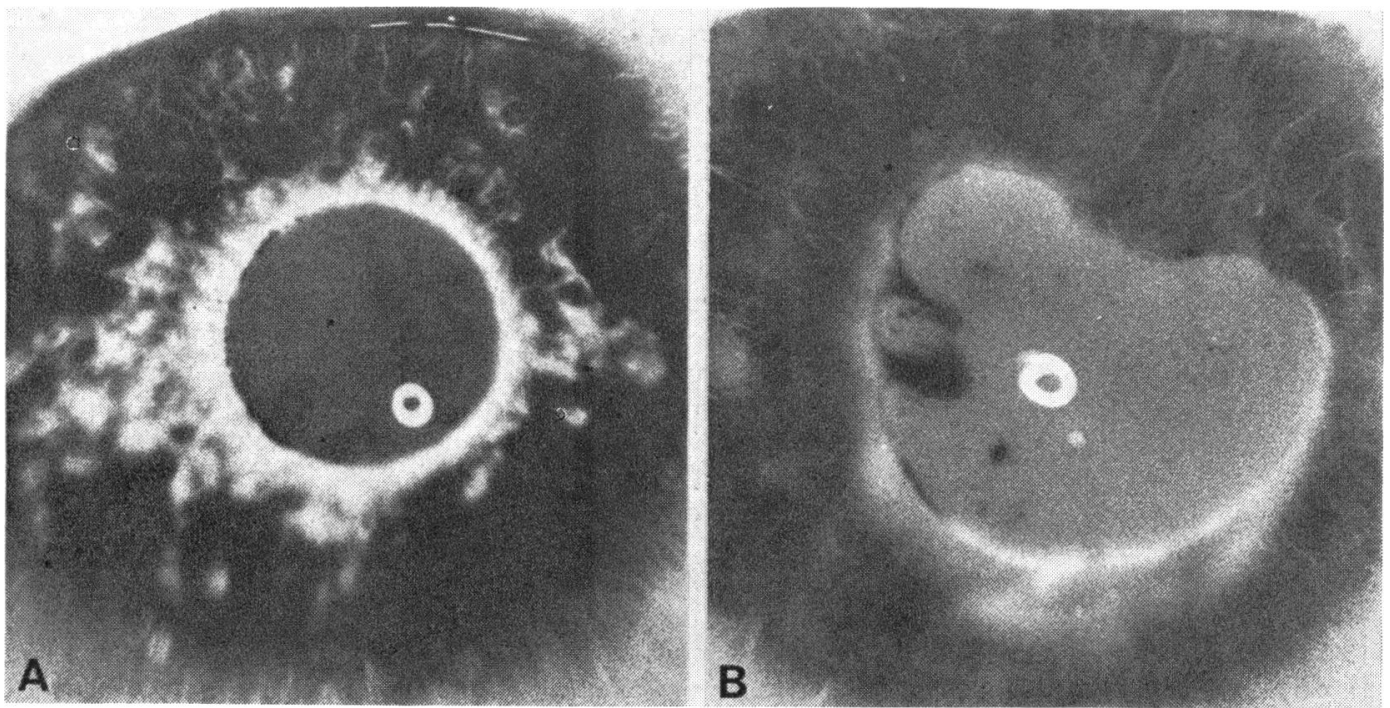

Fig. 2 Case 8. Pretreatment iris fluorescein angiogram. (A) Considerable leakage from new formed vessels around pupil. (B) Same iris four months later after retinal photocoagulation, late picture. Mild fluorescein leakage but virtual obliteration of iris neovascularisation

retinal artery occlusion six years before. This patient was, however, not seen at the acute stage, so possibly the acute episode was an ischaemic type of CRVO. The vision was perception of light only and the IOP varied from 31 to $52 \mathrm{mmHg}$. There was some transient pain although the eye looked quiet. Some rubeosis was seen on the iris, particularly in the chamber angle. Fluorescein angiography showed areas of neovascularisation and considerable leakage from the new formed vessels (Fig. 4 A, B). After retinal panphotocoagulation the IOP remained at about $30 \mathrm{mmHg}$ and the eye was painless. There was no visible rubeosis, although some new vessels were still seen in the fluorescein angiogram (Fig. 4 C, D). The leakage, however, was less pronounced than it was before photocoagulation.

Case 10 (Table) represented an eye with diabetic 

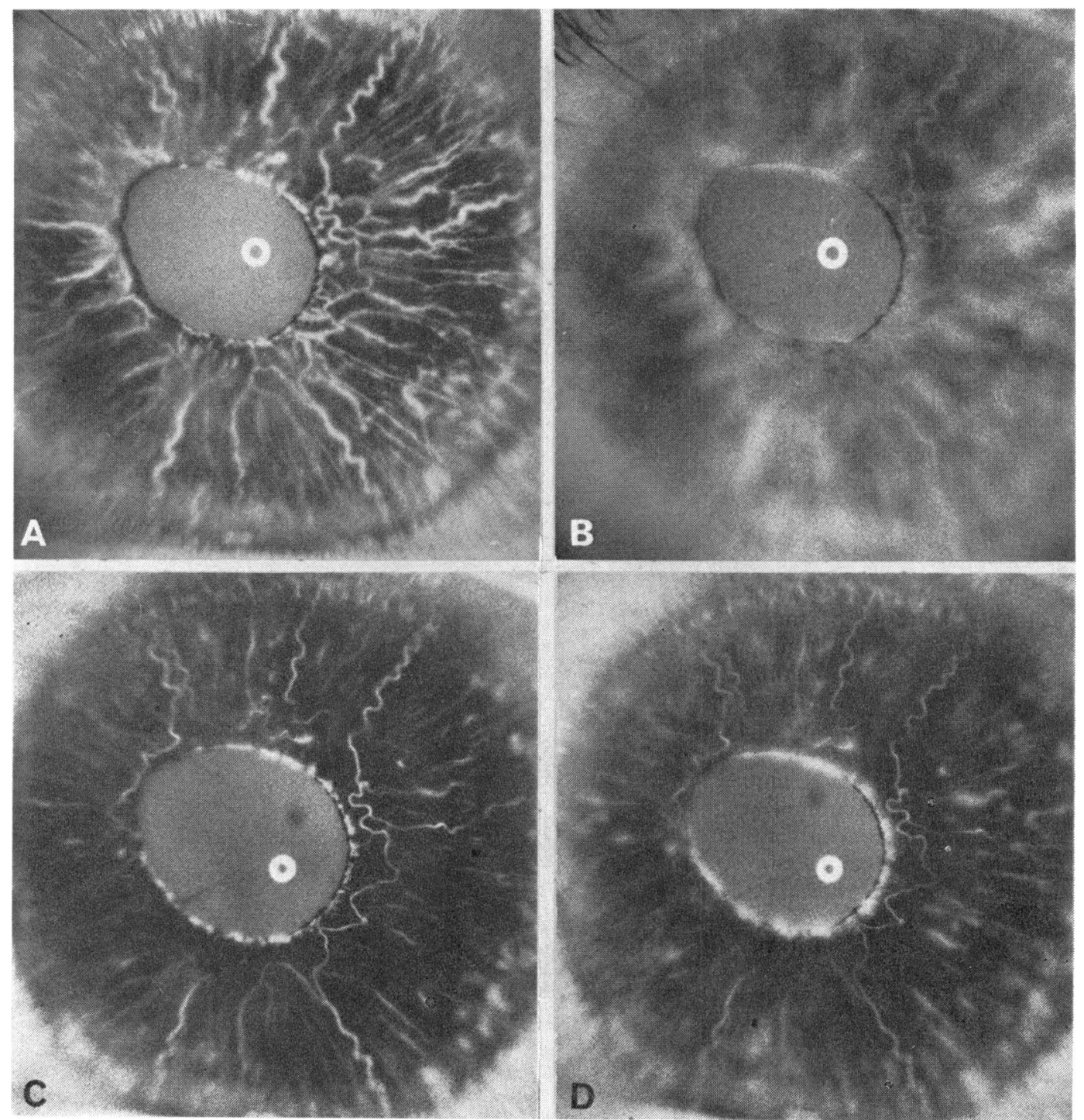

Fig. 3 Case 5. (A, B) Pretreatment iris fluorescein angiogram. Dilatation of iris vessels (A) with remarkable leakage of dye (B). (C, D) Same iris one month after retinal photocoagulation. Considerably less congestion (C) and leakage (D) than before treatment

retinopathy and optic disc neovascularisation. At the same time pronounced iris neovascularisation developed (Fig. 5 A, B). The anterior chamber angle was open, however, in spite of small new formed vessels crossing the angle, and the IOP was normal. Retinal panphotocoagulation was performed. Eight months after treatment iris neovascularisation was not clinically visible. Fluorescein angiography showed only remnants of the previous new vessels and these did not leak fluorescein (Fig. 5 C, D). The visual acuity of this eye subsequently deteriorated because of vitreous haemorrhage from persistent disc neovascularisation.

\section{Discussion}

Abnormalities in the iris vasculature after CRVO appear as abnormal vascular permeability associated with vessel dilatation or neovascularisation, or both (Raitta, 1968; Raitta and Vannas, 1969; 

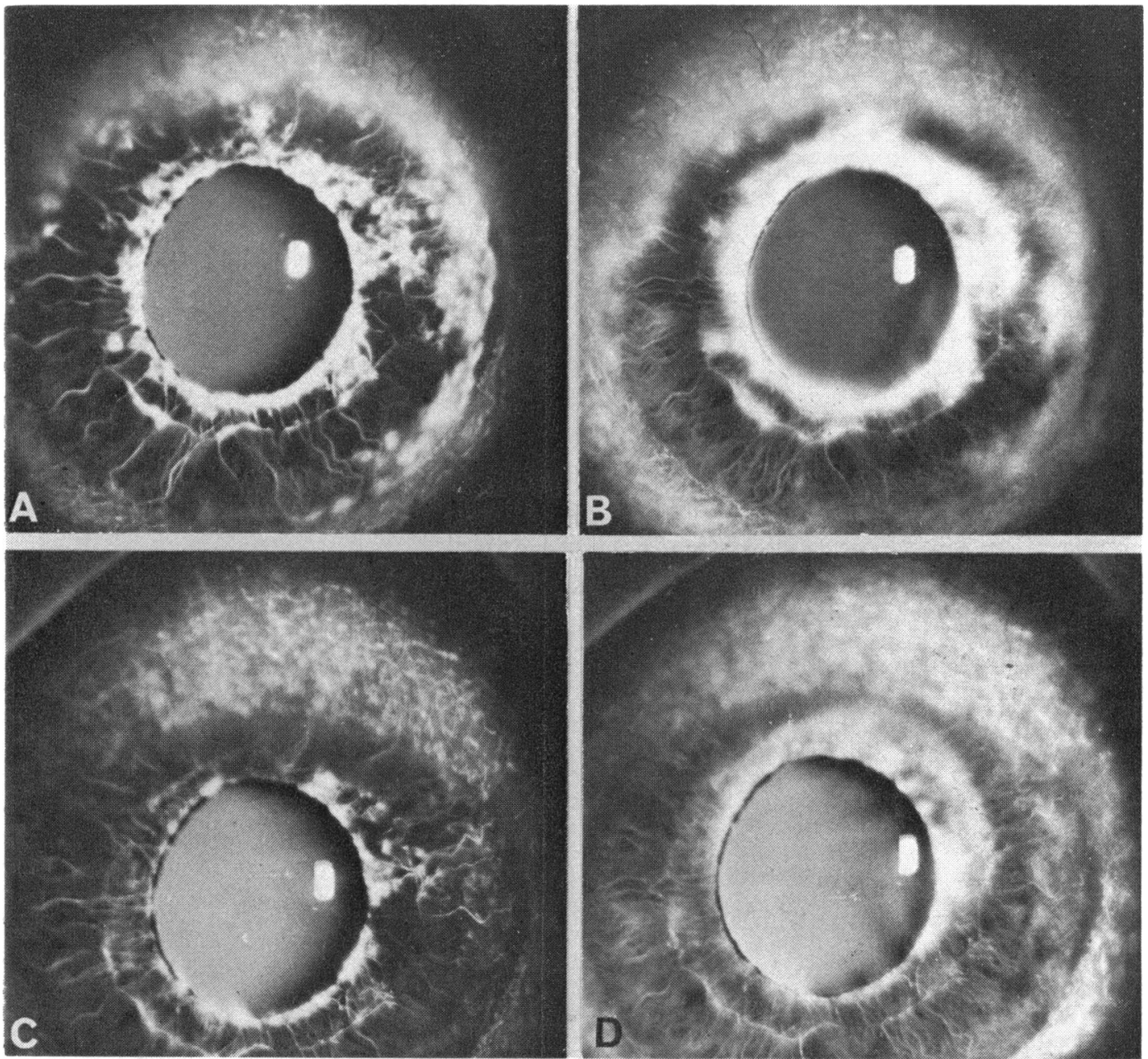

Fig. 4 Case 9. (A, B) Pretreatment iris fluorescein angiogram. Considerable neovascularisation on pupillary margin and iris periphery (A) and leakage of fluorescein from new formed vessels (B). (C, D) Same iris one month after retinal photocoagulation. Considerable regression of rubeosis (C) and only mild leakage (D)

Cappin and Whitelocke, 1974; Kottow, 1976; Laatikainen and Blach, in press). Venous congestion and abnormal permeability with or without capillary closure are also the main features in the retina in CRVO. Corresponding clinical studies on the vessels of the ciliary body have not been possible, but they may also be affected. As a result, the anterior chamber may become shallow and the angle closed after retinal venous occlusion even before iris neovascularisation develops. In three of the eyes an acute angle closure and a raised IOP were found before fibrovascular synechiae developed in significant amounts. Similar cases with an angle-closure attack precipitated by CRVO were described by Cappin and Whitelocke (1974).

After retinal panphotocoagulation abnormal leakage of both radial and new formed iris vessels decreased. In some cases iris neovascularisation was obliterated after treatment and in the others further progression of rubeosis iridis was prevented by photocoagulation. At the same time the IOP rapidly became normal in all the eyes in which the angle was not completely closed by anterior synechiae.

The stimulus for iris neovascularisation is not known. After CRVO more iris vessel changes develop in eyes with fundus neovascularisation (which is known to be caused by retinal capillary 

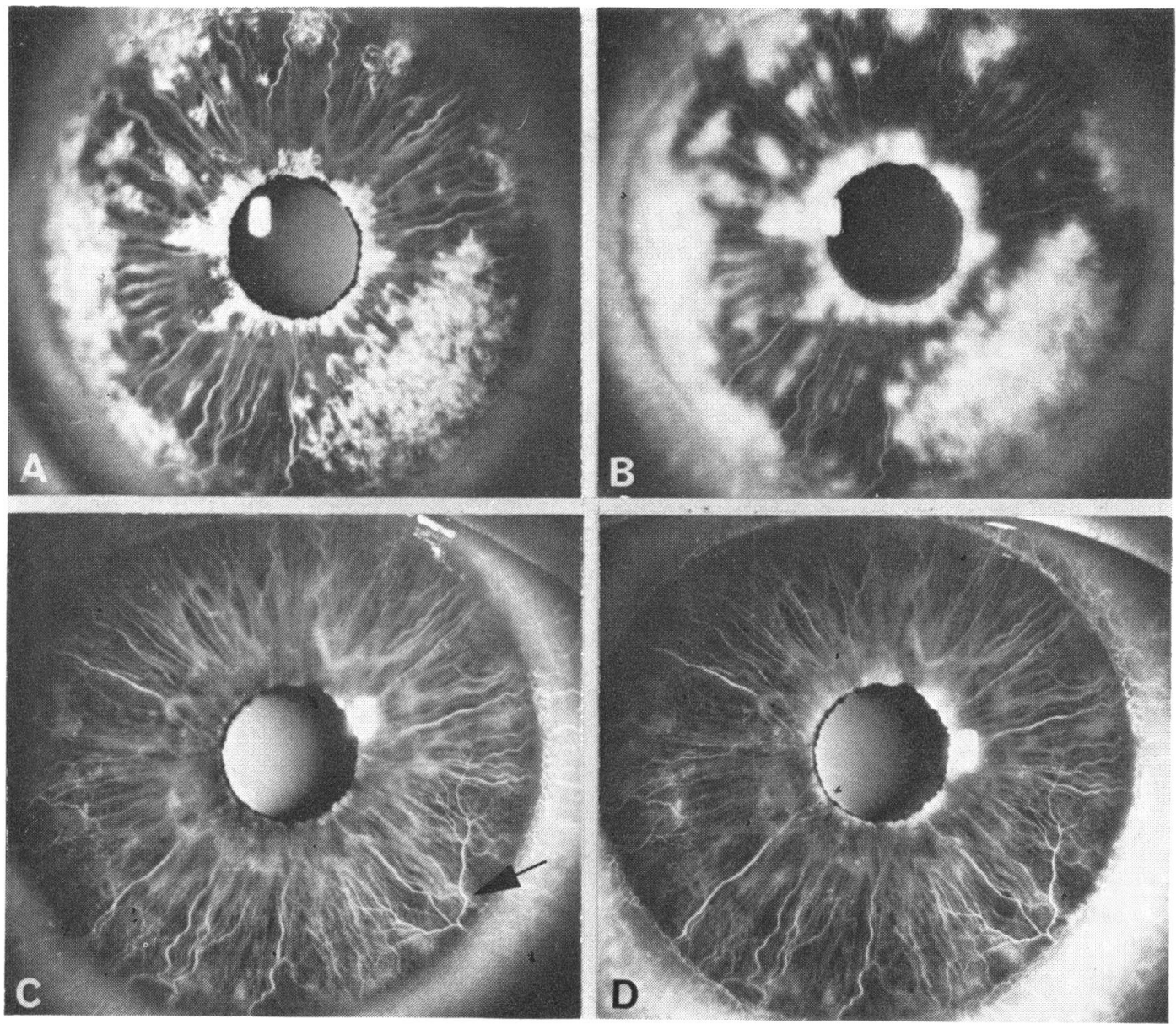

Fig. 5 Case 10. (A, B) Pretreatment iris fluorescein angiogram. Extensive neovascularisation (A) and leakage of dye from new formed vessels (B). (C, D) Same iris eight months after retinal photocoagulation showing obliteration of neovascularisation (C) and virtually no fluorescein leakage (D). Some abnormal big vessel trunks still present on iris periphery (arrow) but do not leak fluorescein

non-perfusion) than in those without (Kottow, 1976). In a recent fluorescein angiographic study we found a close correlation between iris changes and retinal capillary closure (Laatikainen and Blach, in press). These findings support the hypothesis that chronic retinal hypoxia is a cause of rubeosis iridis, as suggested by Ashton (1961) and Smith (1961). Retinal panphotocoagulation results in retinal atrophy instead of hypoxia and disappearance of the presumptive vasoformative stimulus. The posttreatment atrophy corresponds to that caused by acute central retinal artery occlusion or secondary arterial insufficiency and retinal atrophy spontaneously developing in many cases of diabetic retinopathy, or even in the ischaemic type of retinal venous occlusion in which iris neovascularisation sometimes disappears spontaneously.

Most of the treated eyes in the present series had initially very poor vision, and in some cases it deteriorated further during the follow-up. All eyes, however, have been quiet and painless since photocoagulation and most have not required any other therapy for neovascular glaucoma. These results suggest that photocoagulation may have a potential prophylactic and therapeutic role in rubeosis iridis and early neovascular glaucoma so long as the ocular media are clear and the pupil can be dilated.

I thank Mr R. K. Blach for supervising the study and advising on the preparation of the manuscript. 
I am grateful to Mr K. S. Sehmi, who took most of the photographs.

This work was supported by the Francis and Renee Hock Foundation.

\section{References}

Ashton, N. (1961). Transactions of the Ophthalmological Societies of the United Kingdom, 81, 145.

Cappin, J. N., and Whitelocke, R. (1974). Proceedings of the Royal Society of Medicine, 67, 1048.

Kohner, E. M., and Shilling, J. S. (1976). In Medical Ophthalmology, p. 391. Edited by F. Clifford Rose. Chapman and Hall: London.
Kottow, M. H. (1976). Documenta Ophthalmologica, 9, 465.

Laatikainen, L., and Blach, R. K. (1977). British Journal of Ophthalmology. (In press.)

Laatikainen, L., and Kohner, E. M. (1976). British Journal of Ophthalmology, 60, 411.

Raitta, C. (1968). Acta Ophthalmologica, 46, 207.

Raitta, C., and Vannas, S. (1969). Albrecht von Graefes Archiv für Klinische und Experimentelle Ophthalmologie, 177, 33.

Schulze, R. R. (1967). American Journal of Ophthalmology, 63, 487.

Smith, R. (1961). Transactions of the Ophthalmological Societies of the United Kingdom, 81, 125.

Taylor, E. (1970). British Journal of Ophthalmology, 54, 535. 